Article

\title{
Prevention of Periodontitis by the Addition of a Bactericidal Particulate Glass/Glass-Ceramic to a Dental Resin: A Pilot Study in Dogs
}

\author{
Roberto López-Píriz ${ }^{1}$ (D) , Luis A. Díaz ${ }^{1}$, Belén Cabal ${ }^{1,2, *(\mathbb{D})}$, Adolfo Fernández ${ }^{1}$, Marta Suárez ${ }^{1,2}$, \\ Raquel Díaz ${ }^{1}$, Ramón Torrecillas ${ }^{1}$ and José S. Moya ${ }^{1}$ \\ 1 Nanomaterials and Nanotechnology Research Center (CINN-CSIC), Universidad de Oviedo (UO), \\ Principado de Asturias, Avda. de la Vega 4-6, 33940 El Entrego, Spain; lopezpiriz@gmail.com (R.-L.P.); \\ la.diaz@cinn.es (L.A.D.); a.fernandez@cinn.es (A.F.); m.suarez@cinn.es (M.S.); r.diaz@cinn.es (R.D.); \\ r.torrecillas@cinn.es (R.T.); jsmoya@icmm.csic.es (J.S.M.) \\ 2 Nanoker Research, Pol. Ind., Olloniego, Parcela 22A, Nave 5, 33660 Oviedo, Spain \\ * Correspondence: b.cabal@cinn.es
}

Received: 27 June 2018; Accepted: 22 July 2018; Published: 25 July 2018

\begin{abstract}
The aim of the study is to evaluate, in a ligature-induced periodontitis model, the efficacy of a commercially available dental resin containing different antimicrobial glass/glass-ceramic additions $(0-26 \mathrm{wt} . \%)$. It has been proved that a $26 \mathrm{wt} . \%$ glass addition to a conventional dental resin matrix does not alter neither its workability nor its adhesion to the surface of teeth; however, it does confer notable antimicrobial properties when tested in vitro. Moreover, in vivo tests in Beagle dogs demonstrated the prevention of bone loss in ligature-induced plaque accumulation around teeth. Particularly, the glass-ceramic filler resin composite has shown excellent antimicrobial control since it displays the same bone loss as that of the negative control. The results obtained in the present investigation have shown that a conventional dental resin containing a fraction of glass/glass-ceramic ( $\geq 26 \mathrm{wt} . \%$ ) can prevent periodontitis, which is considered to be a most serious dental disease.
\end{abstract}

Keywords: periodontitis; bactericidal glass/glass-ceramic; dental materials; dental composites

\section{Introduction}

Within the past few years, the rates of periodontal and peri-implant disease have increased exponentially, boosted by population ageing, chronic diseases and people's current lifestyle (stress, obesity, bad habits, etc.). Periodontal diseases include gingivitis and periodontitis which are infectious diseases in nature. In developed countries, about $60 \%$ of people over 30 suffer from this condition, which represents the main cause of tooth loss in adult patients. Furthermore, there is growing evidence of a possible association between periodontitis and various systemic diseases and conditions such as respiratory disease, chronic kidney disease, rheumatoid arthritis, cognitive impairment, adverse pregnancy outcomes, obesity, metabolic syndrome and cancer [1]. Preventing the progression of these serious health concerns is thus of critical importance.

It may be difficult to comprehend how to prevent and treat periodontal diseases without knowledge of the key-stone role of bacterial plaque. Since Silness et al. [2] proved the relationship between oral bacteria and gingivitis, the concept of the role of bacteria in periodontal disease etiology has evolved from the "specific and nonspecific plaque hypothesis" [3] to the concept of the opportunistic or ecological nature of periodontal microbiota [4]. Today we know that many of the microorganisms involved in periodontal diseases are uncultivable but identifiable through advanced nucleic acid probe technologies. They make up the periodontitis-associated microbiota 
and are organized in microbial clusters which have the potential to disrupt host defenses and induce an immune reaction that ultimately leads to soft and hard periodontal tissue breakdown.

Traditional methods of periodontal prevention and treatment are based on bacterial control by mechanical removal. Dental scaling and root planning aim to remove supragingival and subgingival calcified deposits, to reduce subgingival biofilm and also to detach and eliminate loosely bound endotoxin from root surfaces, thus restoring sufficient biocompatibility to facilitate healing by the formation of a long junctional epithelium [5]. However, the mechanical treatment of periodontal disease, whether surgical or non-surgical, is limited principally by its inability to completely eliminate pathogenic bacteria from the periodontal tissues, thereby affecting a sustained shift towards a nonpathogenic subgingival microflora. As a consequence, recolonization of treated periodontal sites by pathogenic bacteria following root-surface debridement is associated with poorer therapeutic outcomes. The principal sources of re-infection are endogenous and include the sequestration of organisms within the residual biofilm at poorly accessible sites, such as furcation and within root grooves, invasion of epithelial cells by certain pathogens and recolonization of periodontal sites from other oral niches [6]. As a matter of fact, there is insufficient evidence to determine the effects of routine scale and polish treatments [7].

The aforementioned limitations prompted the use of antimicrobial drugs as adjunctive chemical methods for eliminating periodontal bacteria. However, most local antimicrobial delivery systems have had limited success because of the lack of substantivity from sustained-release devices and their tendency to facilitate bacterial resistance. On the other hand, the use of systemic antibiotics remains highly controversial, except in the management of aggressive periodontitis, as a result of issues related to its ecological impact on microbiome [8,9]. However, due to the importance of bacterial control in periodontal disease treatment, novel adjunctive antimicrobial approaches have emerged within the scientific and clinical literature in recent years. These include photodynamic therapy, prebiotics and probiotics, and the "one-stage full-mouth disinfection" clinical approach $[10,11]$. However, the long term efficacy of these approaches remains unclear. In this regard and attending to the emerging importance of bioactive glasses as antimicrobials, we have explored the role of new bioactive glasses in the prevention of periodontal disease in an in vivo experimental study.

For research purposes, the ligature model has been extensively used in preclinical studies on experimental periodontitis to promote tissue breakdown in a short period of time [12]. The placement of a ligature in a subgingival position disrupts the soft tissue seal around teeth and implants and opens the pocket for biofilm formation. While a ligature made of cotton or silk may not induce bone loss by itself, the developing inflammatory process in the connective tissue that results from biofilm formation mediates tissue destruction during the experiment [13].

A new generation of inorganic biocides based on $\mathrm{CaO}$-enriched soda-lime glasses and $\mathrm{ZnO}$-rich glasses has been recently developed [14,15]. These glasses are suitable for application in several strategic fields in which the control of an unwanted heterogeneous microbial population represents a serious threat to human health. The efficacy of a coating made of this kind of glasses to prevent peri-implant diseases was recently pointed out in a previous in vivo research study [16].

Furthermore, in our previous works [17-19], a new glass-ceramic composed of combeite and nepheline in a residual soda-lime glassy matrix was fabricated by sintering at $750{ }^{\circ} \mathrm{C}$ for $1 \mathrm{~h}$. The antibacterial activity of this glass-ceramic, free of $\mathrm{P}_{2} \mathrm{O}_{5}$, effectively diminishes the growth (logarithm of reduction $>3$ ) of bacteria (such as S. aureus, E. coli, S. epidermidis, M. lutea, and P. aeruginosa) [17] as well as yeast (C. krusei) [18]. It has also been shown that this glass-ceramic inhibits adhesion and biofilm formation [17]. Furthermore, in vitro biocompatibility assays with human stem cells demonstrated that the new glass-ceramic also shows excellent biocompatibility [17].

The main objective of the present work is to study the influence of an antimicrobial glass/glass-ceramic addition, similar to the ones mentioned before, to a flowable resin composite. The addition of a glass-ceramic or a particulate glass containing a high $\mathrm{ZnO}$ fraction to a conventional dental polymer composite can play and important role in preventing periodontitis. To this end, 
in vivo experiments have been carried out on Beagle dog fangs subjected to a ligature-induced periodontitis model.

\section{Materials and Methods}

\subsection{Glass/Glass-Ceramic Synthesis and Characterization}

A glass and glass-ceramic were prepared in a similar way to that previously described by the authors $[14,15,17]$. Briefly, a glass powder from the $\mathrm{SiO}_{2}-\mathrm{Na}_{2} \mathrm{O}-\mathrm{Al}_{2} \mathrm{O}_{3}-\mathrm{CaO}-\mathrm{B}_{2} \mathrm{O}_{3}$ system with the following chemical composition was used (wt.\%): $41.6 \mathrm{SiO}_{2}, 20.0 \mathrm{Na}_{2} \mathrm{O}, 19.5 \mathrm{CaO}, 10.1 \mathrm{Al}_{2} \mathrm{O}_{3}, 6.4 \mathrm{~B}_{2} \mathrm{O}_{3}$, $0.21 \mathrm{MgO}$, and $0.61 \mathrm{~K}_{2} \mathrm{O}$ (Nanoker Research, Oviedo, Spain). The precursor powder was thermally treated in a conventional furnace in air at $750{ }^{\circ} \mathrm{C}$ for $1 \mathrm{~h}$ at a heating rate of $5{ }^{\circ} \mathrm{C} /$ min leading to glass-ceramic material. After thermal treatment, the powders were ground in an alumina mortar and subsequently sieved through a $<40 \mu \mathrm{m}$ mesh. The average particle size obtained, as measured using a laser technique (LS Particle Size Analyzer 13 320, Beckman Coulter, Indianapolis, IN, USA), was found to be $d_{50}=10.30 \pm 0.55 \mu \mathrm{m}$ (Table 1). This glass-ceramic was labelled as G3-GC.

Table 1. Particles size distributions (in volume percentages) of G3-GC and 35ZnO-G. $d_{10}, d_{25}, d_{50}, d_{75}$, $d_{90}$ : particle diameters corresponding respectively to $10 \%, 25 \%, 50 \%, 75 \%$, and $90 \%$ of the cumulative size distribution curve.

\begin{tabular}{cccccc}
\hline Sample & $d_{\mathbf{1 0}}(\mu \mathrm{m})$ & $d_{\mathbf{2 5}}(\mu \mathrm{m})$ & $d_{\mathbf{5 0}}(\mu \mathrm{m})$ & $d_{\mathbf{7 5}}(\mu \mathrm{m})$ & $d_{\mathbf{9 0}}(\mu \mathrm{m})$ \\
\hline G3-GC & 4.29 & 6.08 & 10.30 & 26.75 & 37.27 \\
35ZnO-G & 1.93 & 4.73 & 7.53 & 10.39 & 12.77 \\
\hline
\end{tabular}

A zinc-containing glass, belonging to the $\mathrm{B}_{2} \mathrm{O}_{3}-\mathrm{SiO}_{2}-\mathrm{Na}_{2} \mathrm{O}-\mathrm{Al}_{2} \mathrm{O}_{3}-\mathrm{ZnO}$ system, and with the following chemical composition (wt.\%): $19.39 \mathrm{SiO}_{2} ; 34.24 \mathrm{~B}_{2} \mathrm{O}_{3} ; 5.55 \mathrm{Na}_{2} \mathrm{O} ; 5.13 \mathrm{Al}_{2} \mathrm{O}_{3}$ and $34.73 \mathrm{ZnO}$ was prepared by fusion of mixtures of $\mathrm{Na}_{2} \mathrm{CO}_{3}, \mathrm{SiO}_{2}, \mathrm{~B}_{2} \mathrm{O}_{3}, \mathrm{ZnO}$ and $\mathrm{Al}_{2} \mathrm{O}_{3}$ in Pt crucibles at $1250{ }^{\circ} \mathrm{C}$ for $1 \mathrm{~h}$ in an electric furnace. After melting, it was quenched by dipping the crucible into water, dried, grinded in an alumina mortar and sieved down to $40 \mu \mathrm{m}$. The average particle size (Beckman Coulter LS Particle Size Analyzer 13 320) was found to be $d_{50}=7.53 \pm 0.1 \mu \mathrm{m}$ (Table 1). This glass powder was labelled as 35ZnO-G.

\subsection{Composite Synthesis and Characterization}

A commercially available flowable dental composite Filtek ${ }^{\mathrm{TM}}$ Supreme XTE Flowable Restorative (3M ESPE, St. Paul, MN, USA) was reinforced with varying amounts of the antimicrobial glass/glass-ceramic $(0,13,26 \mathrm{wt} . \%)$. This resin, according to its manufacturer, contains: bis-GMA, TEGDMA and Procrylat resins and the inorganic filler loading is approximately $65 \%$ by weight ( $46 \%$ by volume).

Plates of dimensions $1.5 \mathrm{~cm} \times 1.5 \mathrm{~cm}$ were prepared by homogeneously mixing the resin composite with 13, 26 wt.\% of glass/glass-ceramic powders. Light curing was performed according to the manufacturers' instructions. Photopolymerization was performed using a curing lamp (BA optimal 10, B.A International, Kingsthorpe, UK). The glass-ceramic or glass composites were labelled as G3-GC13, G3-GC26, 35ZnO-G13, 35ZnO-G26.

The obtained composite was analyzed by means of FESEM and EDS analysis to evaluate the homogeneity of particle dispersion. The analyses were performed both on sample surfaces and cross-sections. For cross-section evaluation, the composites were cut with a cut-off machine (TM3-A Boccadoro, Losone, Switzerland) and subsequently polished down to $1 \mu \mathrm{m}$.

\subsection{In Vitro Antibacterial Test}

Previous to the in vivo test, the bactericidal efficacy of the resin composites was evaluated according to ISO 22196:2011 [20]. This standard specifies a method of evaluating the antibacterial 
activity of antibacterial treated plastics and other non-porous product surfaces. ISO 22196:2011 recommends using Staphylococcus aureus (ATCC 6538P) and Escherichia coli (ATCC 8739) bacterial species for the bactericidal capability test. The analysis was performed in triplicate. For each microorganism, 3 specimens of the untreated material (control) were used to measure viable cells immediately after inoculation and another 3 specimens of the untreated material (control) were used to measure viable cells after $24 \mathrm{~h}$ of incubation. 3 specimens of each treated test material were used to measure viable cells after $24 \mathrm{~h}$ of incubation.

The square test composites $(1.5 \mathrm{~cm} \times 1.5 \mathrm{~cm})$ : 6 untreated resins and 3 filled with glass/glass-ceramic composites were placed in petri dishes and inoculated with $50 \mu \mathrm{L}$ of the test inoculum (containing $2.7 \times 10^{5} \mathrm{CFU} / \mathrm{mL}$ of Escherichia coli or $4.5 \times 10^{5} \mathrm{CFU} / \mathrm{mL}$ of Staphylococcus aureus). The inoculum was covered with a sterile polyethylene coverslip $(1.4 \mathrm{~cm} \times 1.4 \mathrm{~cm})$, which allows the inoculum to spread well, prevents it from drying and ensures good contact with the antimicrobial surface. Immediately after inoculation, half of the untreated composites were supplied with $5 \mathrm{~mL}$ of phosphate-buffer saline to recover bacteria from the surface of the specimens. The recovered bacteria cell suspension was then serially diluted in physiological saline. Petri dishes containing plate count agar were inoculated with these recovered bacterial dilutions in duplicate. These plates were incubated for $24-48 \mathrm{~h}$ at $37^{\circ} \mathrm{C}$, after which CFU were determined. The remaining 3 untreated and glass/glass-ceramic composites were incubated for $24 \mathrm{~h}$ at $37^{\circ} \mathrm{C}$ and $95 \%$ humidity. After this time, the bacterial cells were recovered from the surface and the number of microorganisms present on the surfaces was determined in the way previously described. The reduction in microorganisms in relation to the initial concentrations and the control surface was calculated. Antibacterial activity, delineated as $R$, was calculated following Equation:

$$
R=\left(U_{t}-U_{0}\right)-\left(A_{t}-U_{0}\right)=U_{t}-A_{t}
$$

where $R$ is antibacterial activity; $U_{0}$ is the average logarithm of the number of viable bacteria, in cells $/ \mathrm{cm}^{2}$, recovered from untreated test specimens immediately after inoculation; $U_{t}$ is the average logarithm of the number of viable bacteria, in cells $/ \mathrm{cm}^{2}$, recovered from untreated test specimens after $24 \mathrm{~h}$; and $A_{t}$ is the average logarithm of the number of viable bacteria, in cell $/ \mathrm{cm}^{2}$, recovered from treated test specimens after $24 \mathrm{~h}$.

Converting logarithmic (base 10) reduction $R$ to percentage reduction $(P)$ is possible applying the following formula: $P=100 \times\left(1-10^{-R}\right)$. This means that the $R$-values (log10 scale) of 1,2 , $3,4,5$ and 6 correspond to microbial load reductions of $90 \%, 99 \%, 99.9 \%, 99.99 \%, 99.999 \%$ and $99.9999 \%$, respectively.

\subsection{In Vivo Test}

\subsubsection{Animals}

This study was carried out in strict accordance with Directive 2010/63/EU on the protection of animals used for scientific purposes. The protocol was approved by the Ethics Committee for Animal Research Welfare of the Minimally Invasive Surgery Center (Cáceres, Spain). Five Beagle dogs were used in this experiment to meet the goal of reduction, the second of the 3R's (Replacement, Reduction and Refinement), a widely accepted ethical framework for conducting scientific experiments. In addition, it is common practice to employ this number of animals for such experiments and thus satisfy statistical power requirements. At the initiation of the experiment, the dogs were 5 years old and weighed $19 \mathrm{~kg}$ on average.

During all procedures, veterinary assistance was used continuously and all efforts were made to minimize suffering. General anaesthesia was induced with intravenous injected propofol $10 \mathrm{mg} / \mathrm{kg}$ (Propofol Hospira, Hospira Productos Farmacéuticos y Hospitalarios, Madrid, Spain). One no. 7 endotracheal tube with a balloon cuff was placed and connected to a circular anesthesia circuit (Leon Plus, Heinen \& Löwenstein, Bad Ems, Germany). The anesthesia was sustained with sevofluorane 
(Sevorane, Abbott Laboratories, Madrid, Spain). Multimodal analgesia was employed in the perioperatory [ketorolac $1 \mathrm{mg} / \mathrm{kg}$ (Toradol $30 \mathrm{mg}$, Roche, Basel, Seitzerland), tramadol $1.7 \mathrm{mg} / \mathrm{kg}$ (Adolonta inyec., Grünenthal, Aachen, Germany) and buprenorfine $0.01 \mathrm{mg} / \mathrm{kg}$ (Buprex, Reckitt Benckiser Pharmaceuticals Limited, Berkshire, UK)].

\subsubsection{Dental Preparations}

Sample size was 20 canines ( 5 dogs) but the study unit was each aspect (medial and distal) of each fang. Negative controls were used to exclude spontaneous bone loss or recession due to any etiology unrelated with the experiments. Negative controls consisted of 2 canines (4 aspects) without intervention (no class $\mathrm{V}$ obturation nor periodontitis ligature induction). Class $\mathrm{V}$ dental preparations (named CV) (Black's classification) were performed in 18 canines (36 aspects) using a $0.5 \mathrm{~mm}$ diameter drill bur (Komet Dental, Lemgo, Germany) and affecting the enamel next to the supra gingival margin all the way around the neck of the crown (Figure 1a). Dental preparations were conditioned by a self-etching one-step primer and bonding solution (3M ESPE ScotchBond Universal Adhesive, St. Paul, MN, USA) that was light-cured for $20 \mathrm{~s}$ (BA optimal 10, B.A International, Kingsthorpe, UK). Consecutively, these preparations were filled with different restorative materials. A universal restorative dental composite (3M ESPE Filtek Supreme XTE, St. Paul, MN, USA) was used as the control material ( $n=6,12$ aspects). In the test branches (for each group $n=6,12$ aspects), G3-GC or $35 \mathrm{ZnO}-\mathrm{G}$ powders were mixed ( $26 \mathrm{wt} . \%$ ) with the commercial dental composite to provide them with antimicrobial properties, as previously described. The mixing was performed by hand with a stainless steel dental cement spatula on a glass slab. Dental materials were randomly allocated. All preparations were filled via incremental addition using a dental spatula (Dental Spatula XTS Composite No 03 Flexi Thin, Hu-Friedy Mfg Co., Chicago, IL, USA) and light-cured.
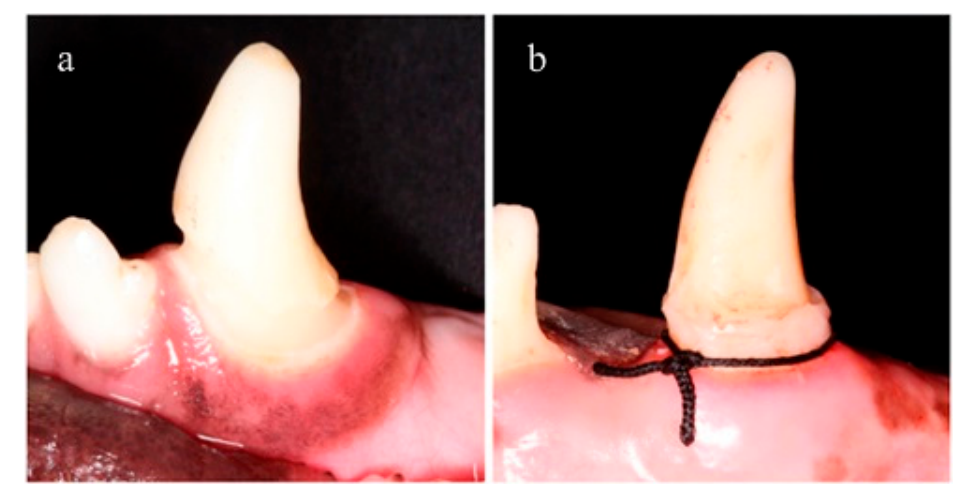

Figure 1. (a) Class V dental preparation of Beagle dogs canines; (b) Traditional ligature to induce periodontitis.

\subsubsection{Experimental Periodontitis}

The traditional ligature model was used to induce acute breakdown of periodontal tissues as described by Lindhe et al. in 1973 [12]. Dental preparations were overfilled to provide retention for ligatures since canines have a conical shape and ligatures tend to slip off and to be loose. Ligatures were placed in a yuxtagingival position and no plaque control procedures were performed (Figure 1b).

\subsubsection{Bone Loss Measurements}

After 8 weeks of ligature periodontitis induction the animals were euthanized with a lethal dose of Sodium-Pentothal. Blocks containing the canines were retrieved from the jaw bone using an oscillating autopsy saw (Exakt, Kulzer, Germany). The dissected specimens were sent to two blinded appraisers who measured the medial and distal aspects of the canines, to assess the distance between the apical portion of the dental restoration and the residual marginal bone level. Distance 
was assessed using a double-pointed compass (EMI Deluxe EKG Caliper, Fullerton, CA, USA) as can be observed in Figure 2. A trained program was implemented to increase inter- and intra-examiner reliability. Mean values for all variables were calculated for the mesial and distal aspect of each tooth. Comparisons were made using absolute values (final bone loss in millimeters). Differences were analyzed using a non-parametric (Mann-Whitney) method. The null hypothesis was rejected at $p \leq 0.05$.

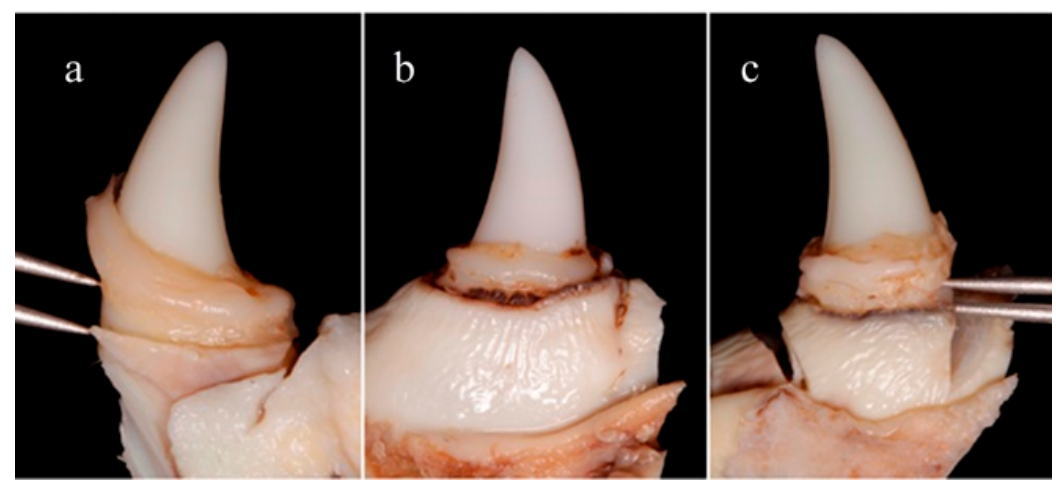

Figure 2. Images of specimens during measurements procedures in teeth with class V obturations with different materials: (a) Commercial dental composite (positive control); (b) Dental composite filled with 26 wt.\% of G3-GC powder; (c) Dental composite filled with 26 wt.\% of 35ZnO-G powder.

The cross-sections of the dissected specimens, after polishing $(<1 \mu \mathrm{m})$, and their corresponding external surfaces were also characterized by Field Emission Scanning Electron Microscopy (FESEM) (FEI: Quanta FEG 650, Hillsboro, OR, USA) and Energy Dispersive Spectroscopy (EDS) equipment from EDAX-AMETEK GmbH (Meerbusch, Germany).

\section{Results}

\subsection{Starting Material Characterization}

According to the manufacturer's general information, the fillers are a combination of ytterbium trifluoride with a particle size range of 0.1 to $5 \mu \mathrm{m}$, a non-agglomerated/non-aggregated surface-modified $75 \mathrm{~nm}$ silica filler and a surface-modified aggregated zirconia/silica cluster filler (comprised of $20 \mathrm{~nm}$ silica and 4 to $11 \mathrm{~nm}$ zirconia particles). The aggregate has an average cluster particle size ranging from 0.6 to $10 \mu \mathrm{m}$ (Figure 3a). In Figure 3b,c the FESEM micrographs corresponding to G3-GC26 and 35ZnO-G26 resin composites are shown. The particle size distributions of both powders are shown in Table 1.

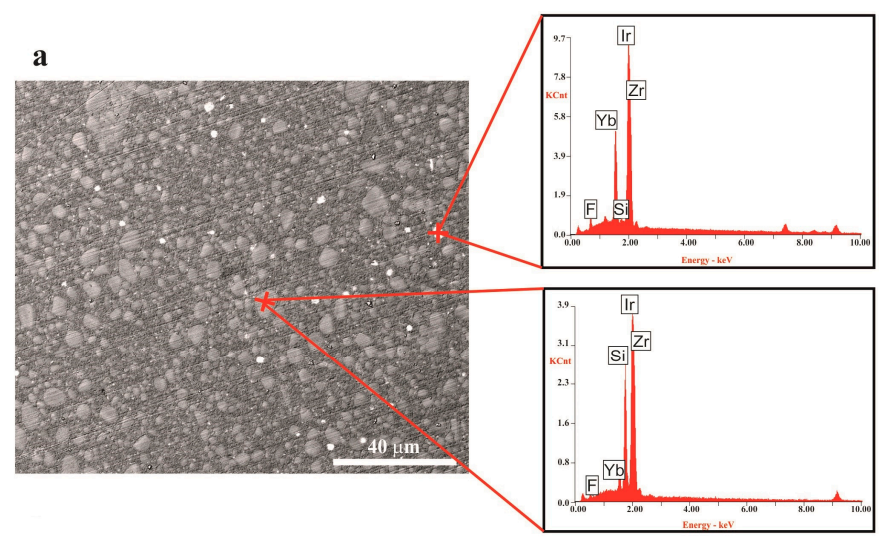

Figure 3. Cont. 
b

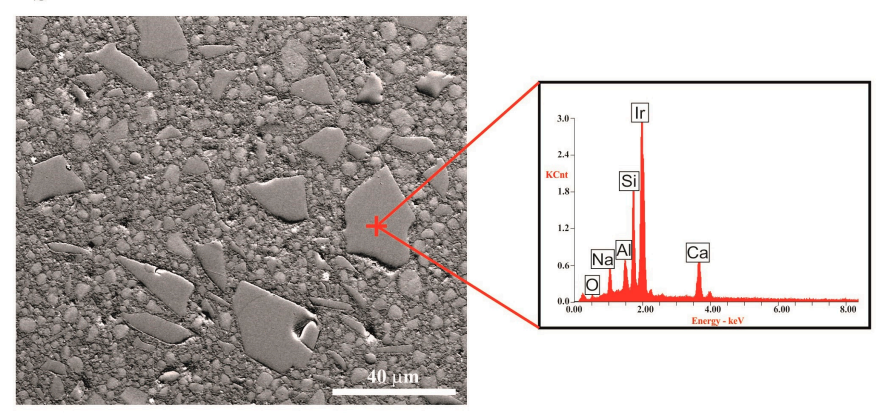

C

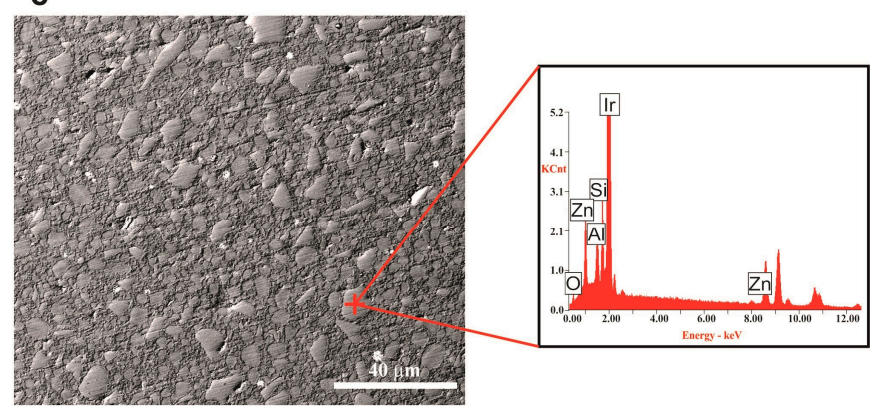

Figure 3. Scanning electron micrographs of the polished cross-sectioned control composite (a) and the corresponding EDS analysis; composite containing G3-GC26 (b) and the corresponding EDS analysis of the G3-GC particles; composite containing 35ZnO-G26 (c) and the corresponding EDS analysis of the $35 \mathrm{ZnO}-\mathrm{G}$ particles.

\subsection{In Vitro Results}

Composites containing G3-GC and 35ZnO-G showed bactericidal efficacy against the evaluated bacteria (Table 2). Both glasses exhibit dose-dependent killing. The higher the glass content, the higher the bactericidal activity. They were more active against Gram negative bacteria ( $99.9 \%$ of reduction for E. coli vs. $99 \%$ of reduction for S. aureus).

Table 2. In vitro antimicrobial activity: $U_{t}$ is the average of the common logarithm of the number of viable bacteria, in cell $/ \mathrm{cm}^{2}$, recovered from the untreated test specimens after $24 \mathrm{~h} ; A_{\mathrm{t}}$ is the average of the common logarithm of the number of viable bacteria, in cell $/ \mathrm{cm}^{2}$, recovered from the treated test specimens after $24 \mathrm{~h} . R$ is the antibacterial activity. $R=U_{t}-A_{t}$.

\begin{tabular}{ccccccc}
\hline \multirow{2}{*}{ Sample } & \multicolumn{3}{c}{ E. coli } & \multicolumn{3}{c}{ S. aureus } \\
\cline { 2 - 7 } & $\boldsymbol{U}_{\boldsymbol{t}}$ & $\boldsymbol{A}_{\boldsymbol{t}}$ & $\boldsymbol{R}$ & $\boldsymbol{U}_{\boldsymbol{t}}$ & $\boldsymbol{A}_{\boldsymbol{t}}$ & $\boldsymbol{R}$ \\
\hline G3-GC13 & 4.21 & 2.07 & 2.14 & 3.20 & 2.08 & 1.12 \\
G3-GC26 & 4.21 & 0.70 & 3.51 & 3.20 & 1.41 & 1.80 \\
35ZnO-G13 & 4.21 & 0.77 & 3.44 & 3.20 & 0.35 & 2.85 \\
35ZnO-G26 & 4.21 & 0.35 & 3.86 & 3.20 & 0.35 & 2.85 \\
\hline
\end{tabular}

\subsection{In Vivo Results}

Taking the dose-dependent killing into account, in vivo tests were only carried out using resins with the highest content of glass/glass-ceramic (i.e., 26 wt.\%).

No bone loss was detected at the end of the experiment around negative control teeth. The mean amount of bone loss that occurred at the end of the ligature-induced periodontitis period was found to be $0.92 \mathrm{~mm}$ around positive control teeth; $0 \mathrm{~mm}$ around teeth filled with a dental composite containing G3-GC26 powder and $0.33 \mathrm{~mm}$ around teeth filled with a dental composite containing 35ZnO-G26 
(Table 3). There are significant differences in bone loss between positive controls and G3-GC26 filled teeth ( $p=0.045$ Mann-Whitney) but no statistical differences were found between the controls and 35ZnO-G26 filled teeth ( $p=0.217$ Mann-Whitney). Inter-appraiser and intra-appraiser agreement turned out in Kappa values of 0.84 and 0.92 , respectively.

Table 3. Mean values of bone loss at distal and mesial aspect of teeth filled with different restorative materials in Class V preparations.

\begin{tabular}{ccccc}
\hline Sample & $n$ & Mean & SD & Mann-Whitney \\
\hline Control & 12 & 0.92 & 1.24 & - \\
G3-GC26 & 12 & 0 & 0 & 0.045 \\
35ZnO-G26 & 12 & 0.33 & 0.49 & 0.217 \\
\hline
\end{tabular}

\subsection{Composite Characterization}

The FESEM micrographs corresponding to the external surface of the composite toroid (Figure 4) show that, in both cases (i.e., G3-GC26 and 35ZnO-G26 composites), grains >10 $\mu$ m have been pulled-out leaving a gap. In the case of both filled composites, the grains subjected to continuous abrasion in the dog's mouth and some cracks, probably produced by pull-out (identified with white arrows in Figure 4), are still clearly visible. In the particular case of G3-GC26, almost all grains $<10 \mu \mathrm{m}(\sim 50 \%$ of the volume fraction) have remained, resisting the wear of the dog's tongue without an appreciable dissolution effect (Figure 4a). The dissolution of the grains is more significant in the case of 35ZnO-G26 composites (Figure 4b). Footprints clearly correspond to a sharp contour of the particles.
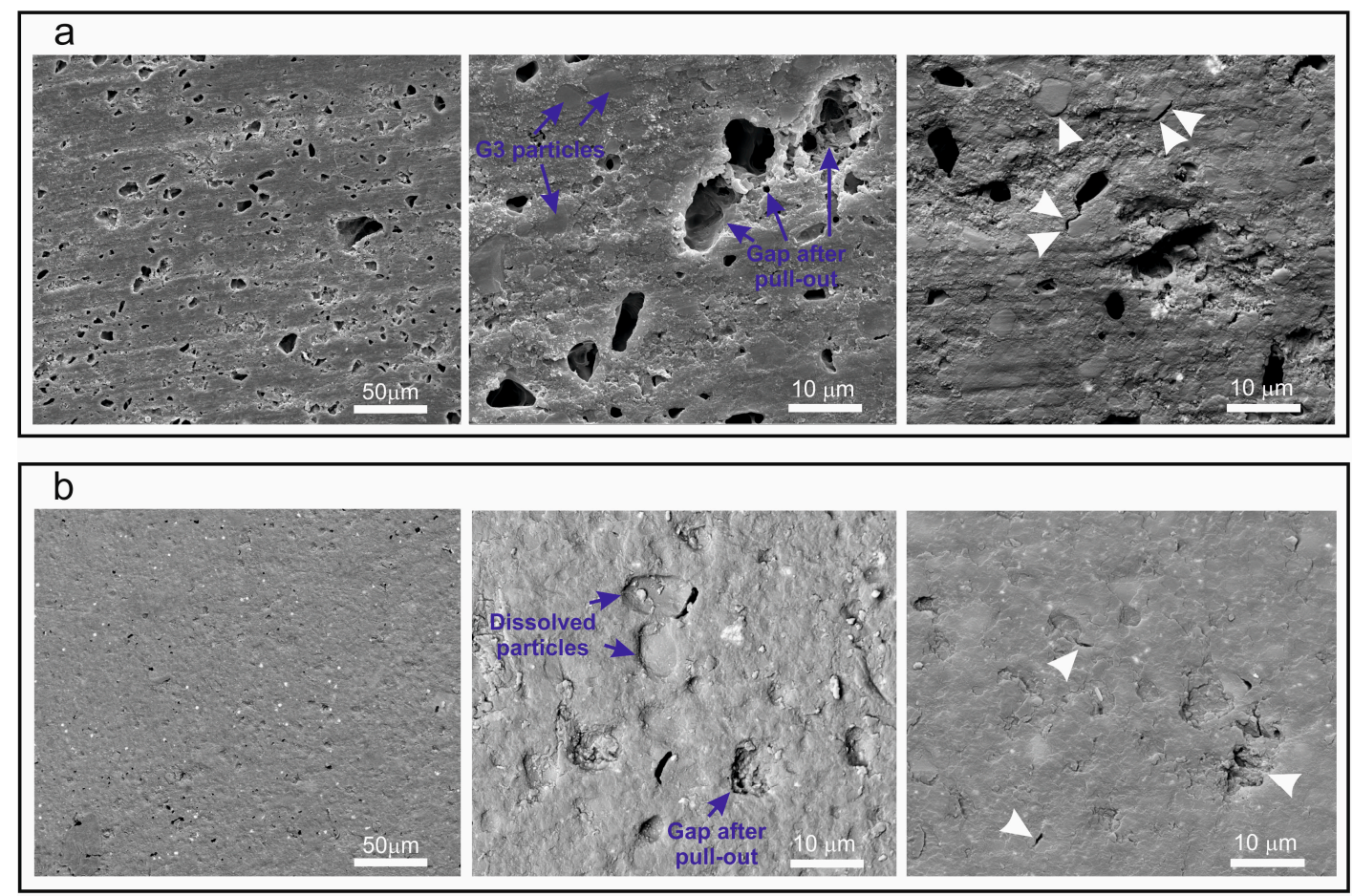

Figure 4. (a) Scanning electron micrographs at different magnifications of the G3-GC26 resin composite external surface; (b) Scanning electron micrographs at different magnifications of the 35ZnO-G26 resin composite external surface. 


\section{Discussion}

Diverse research with different additives has been carried out to develop effective antibacterial resin-based composites. Most of these additives are organic bactericides, such as: quaternary ammonium dimethacrylate (QADM) [21], dimethylaminohexadecyl methacrylates (DMAHDM) [22], dimethyl-hexadecylmethacryloxyethyl-ammonium iodide (DHMAI) [23], quaternary ammonium polyethylenimine (PEI) nanoparticles [24], chlorhexidine [25], triclosan [26] or chitosan [27]. Inorganic coatings have emerged as an alternative approach since they present several advantages compared to traditional organic agents, which include chemical stability, thermal resistance and protracted action, and they have not yet been associated with resistant organisms [28]. Silver is the most studied antibacterial metal ion for the treatment of periodontitis and perimplantitis [29]. The use of different experimental fillers is another important strategy. In this sense, multifunctional bioactive glasses and glass-ceramics could be an alternative antimicrobial system. The bioactivity of the glass/glass-ceramic has made the current composite an interesting candidate for potential applications in the dental field. Tauböck et al. functionalized a dentin bonding resin with $20 \mathrm{wt} . \%$ ultrafine $\mathrm{SiO}_{2}-\mathrm{Na}_{2} \mathrm{O}-\mathrm{CaO}-\mathrm{P}_{2} \mathrm{O}_{5}-\mathrm{Bi}_{2} \mathrm{O}_{3}$ particles. This bioactive glass loading does not influence microhardness, and the viscosity of the composite remained below that of a flowable dental composite [30]. However, it did not evaluate the possibility of conferring antimicrobial properties to the dental resin, at least to the author's knowledge. Khvostenko et al. investigated the effect of adding $15 \mathrm{wt} . \%$ bioglass $\left(65 \% \mathrm{SiO}_{2}-31 \% \mathrm{CaO}-4 \% \mathrm{P}_{2} \mathrm{O}_{5}(\mathrm{~mol} . \%)\right)$ to a resin composite on bacterial biofilms penetrating into marginal gaps of simulated tooth fillings in vitro during cyclic mechanical loading. A significantly lower degree of bacterial biofilm penetration into the gap was found [31]. The results obtained in the present in vivo experiment, although limited by sample size, due to the ethical issues involved in the use of Beagle dogs in in vivo experiments, demonstrate the antimicrobial performance of a dental resin matrix containing different bioglass fillers and can thus expand the clinical applications of these materials in the treatment of dental diseases in the near future.

It has been proven that the concentration required to obtain the desired antimicrobial properties (26 wt.\%) does not compromise tooth-bonding efficacy nor workability. The dental adhesive remained on the tooth until the end of the in vivo test (Figure 2). Further studies are ongoing in order to complete the mechanical characterization.

It is important to point out that both powders display a different particle size distribution as is made clear in Table 1 . The G3-GC26 powder has a larger average grain size $\left(d_{50}=10.3 \mu \mathrm{m}\right)$ and course fraction than the $\mathrm{Zn}$-containing glass $\left(d_{50}=7.5 \mu \mathrm{m}\right)$. Particle distribution was found to be very homogeneous in both cases and no aggregates are observed in the polymer matrix (Figure 3).

Although the bactericidal properties of these glasses have been extensively proved [14,17], in vitro tests were carried out before the in vivo test to ensure that the composites preserve their efficacy. In agreement with the results obtained in vitro, the in vivo tests were performed using the composites containing $26 \mathrm{wt} . \%$ glass or glass-ceramic particulate filler.

At $24 \mathrm{~h}$, time at which the in vitro tests were carried out according to the standard, the composite reinforced with 35ZnO-G26 looks more active than the one containing G3-GC26. This trend can be explained taking into account the different dissolution behavior of the glasses. However, after $72 \mathrm{~h}$, both materials show the same antimicrobial performance [14,17]. Due to differences in microbiological test protocols, previous results obtained by other authors cannot be directly compared to one another or to the results of the present study.

In the FESEM micrographs corresponding to the external surface of the composite toroid (Figure 4), after the in vivo test, we can observe that, in both cases (G3-GC26 and 35ZnO-G26 glass composites), grains $>10 \mu \mathrm{m}$ have been pulled-out leaving a gap. In the particular case of the G3-GC26 glass-ceramic, almost all grains $<10 \mu \mathrm{m}(\sim 50 \%$ of the volume fraction) have remained, resisting the wear of the dog's tongue without an appreciable dissolution effect (Figure 4a). As observed in Figure 3, two crystalline phases precipitate during G3-GC powder annealing at $750{ }^{\circ} \mathrm{C}$ : nepheline $\left(\mathrm{Na}_{6.65} \mathrm{Al}_{6.24} \mathrm{Si}_{9.76} \mathrm{O}_{32}\right)$ and combeite $\left(\mathrm{Na}_{2} \mathrm{Ca}_{2} \mathrm{Si}_{3} \mathrm{O}_{9}\right)$. In a previous study [17], nepheline crystals were described as elongated 
$(>10 \mu \mathrm{m})$ while combeite crystals were found to be equiaxed and much smaller $(<50 \mathrm{~nm})$. The presence of nepheline needle-like crystals drastically improves the wear resistance of this composite. This fact can explain its good behavior in the prevention of the induced periodontitis (Table 3). Therefore, its antimicrobial activity is not significantly affected during the 4 months of testing in the dog's mouth.

Conversely, in the case of the Zn-containing glass composite, 35ZnO-G shows the typical XRD pattern of a perfect glass [14]. Taking into account that its granulometric distribution is noticeably narrower than that corresponding to G3-GC and that it is more soluble, the majority of the grains $<5 \mu \mathrm{m}(\sim 25 \%$ of the volume fraction) were dissolved as a consequence of the continuous abrasion to which it is subjected inside the dog's mouth. It is, therefore, logical to think that the biocidal activity of this composite has been significantly reduced and was most probably limited to the first weeks of implantation. Nevertheless, statistical results $(p=0.217)$ tend to be significant and suggest that with a larger number of subjects more relevant differences might be detected in terms of bone loss between 35ZnO-G and positive control groups.

Since negative controls did not experience any bone loss during the experiment, it can be assumed that the bone loss achieved around positive controls and cases is totally due to experimental ligature-induced periodontitis.

\section{Conclusions}

It has been proved that a $26 \mathrm{wt} . \%$ glass addition to a conventional dental resin matrix does not alter either its workability or its adhesion to the surface of teeth; however, it does confer notable antimicrobial properties when tested in vitro. This performance results in an in vivo prevention of bone loss when plaque accumulation is induced by ligature around the teeth. Particularly, G3-GC26 has shown excellent antimicrobial control since it displays the same bone loss as that of the negative control and prevents bone loss $(p=0.045)$ with respect to the positive control. 35Zn-G26 has shown an excellent in vitro behavior; however, in vivo, it might be affected by the dissolution rate of its glass particles. Statistical results indicate that further experiments with larger sample sizes and a bigger average particle size might display a resounding result. Finally, the results obtained in the present investigation have shown that a conventional dental resin containing a fraction of these glasses ( $\geq 26 \mathrm{wt} . \%)$ can prevent periodontitis, which is considered to be a most serious dental disease.

Author Contributions: Conceptualization, R.-L.P., B.C., R.T. and J.S.M.; Methodology, R.-L.P.; Validation, R.-L.P., B.C., and R.D.; Formal Analysis, R.-L.P. and R.D.; Investigation, R.-L.P., L.A.D., B.C., A.F., M.S. and R.D.; Resources, R.-L.P.; Writing-Original Draft Preparation, R.-L.P., B.C, J.S.M. and R.T.; Writing-Review \& Editing, R.-L.P., L.A.D., B.C, J.S.M. and R.T.; Visualization, L.A.D., B.C., A.F.; Supervision R.-L.P. and J.S.M.; Project Administration, R.-L.P., R.T. and J.S.M.; Funding Acquisition, R.-L.P. and R.T.

Funding: This research received no external funding.

Acknowledgments: Authors acknowledge the Minimally Invasive Surgery Center (Cáceres, Spain) the availability of their facilities for carrying out the surgical procedures.

Conflicts of Interest: The authors declare no conflict of interest.

\section{References}

1. Shangase, S.L.; Mohangi, G.U.; Hassam-Essa, S.; Wood, N.H. The association between periodontitis and systemic health: An overview. SADJ 2013, 68, 10-12.

2. Silness, J.; Löe, H. Periodontal disease in pregnancy II. Correlation between oral hygiene and periodontal condition. Acta Odontol. Scand. 1964, 22, 121-135. [CrossRef] [PubMed]

3. Loesche, W.J. Chemotherapy of dental plaque infections. Oral Sci. Rev. 1976, 9, 65-107. [PubMed]

4. Socransky, S.S.; Haffajee, A.D. Dental biofilms: Difficult therapeutic targets. Periodontology 2000 2002, 28, 12-55. [CrossRef] [PubMed]

5. Drisko, C.L. Periodontal debridement: Still the treatment of choice. J. Evid. Based Dent. Pract. 2014, $14,33-41$. [CrossRef] [PubMed] 
6. Teles, R.P.; Haffajee, A.D.; Socransky, S.S. Microbiological goals of periodontal therapy. Periodontology 2000 2006, 42, 180-218. [CrossRef] [PubMed]

7. Worthington, H.V.; Clarkson, J.E.; Bryan, G.; Beirne, P.V. Routine scale and polish for periodontal health in adults. Cochrane Database Syst. Rev. 2013, 1, CD004625. [CrossRef] [PubMed]

8. Ardila, C.M.; Granada, M.I.; Guzmán, I.C. Antibiotic resistance of subgingival species in chronic periodontitis patients. J. Periodontal Res. 2010, 45, 557-563. [CrossRef] [PubMed]

9. Jepsen, K.; Jepsen, S. Antibiotics/antimicrobials: Systemic and local administration in the therapy of mild to moderately advanced periodontitis. Periodontology 2000 2016, 71, 82-112. [CrossRef] [PubMed]

10. Sagar, A. Full mouth versus quadrant treatment in chronic periodontitis. Prim. Dent. J. 2014, 3, 66-69. [CrossRef] [PubMed]

11. Kellesarian, S.V.; Malignaggi, V.R.; Majoka, H.A.; Al-Kheraif, A.A.; Kellesarian, T.V.; Romanos, G.E.; Javed, F. Effect of laser-assisted scaling and root planing on the expression of pro-inflammatory cytokines in the gingival crevicular fluid of patients with chronic periodontitis: A systematic review. Photodiagn. Photodyn. Ther. 2017, 18, 63-77. [CrossRef] [PubMed]

12. Lindhe, J.; Hamp, S.E.; Löe, H. Experimental periodontitis in the beagle dog. J. Periodontal Res. 1973, 8, 1-10. [CrossRef] [PubMed]

13. Kennedy, J.E.; Polson, A.M. Experimental marginal periodontitis in squirrel monkeys. J. Periodontol. 1973, 44, 140-144. [CrossRef] [PubMed]

14. Esteban-Tejeda, L.; Prado, C.; Cabal, B.; Sanz, J.; Torrecillas, R.; Moya, J.S. Antibacterial and antifungal activity of ZnO containing glasses. PLoS ONE 2015, 10, e0132709. [CrossRef] [PubMed]

15. Moya, J.S.; Esteban-Tejeda, L.; Pecharromán, C.; Mello-Castanho, S.R.H.; Da Silva, A.C.; Malpartida, F. Glass powders with a high content of calcium oxide: A step towards a "green" universal biocide. Adv. Eng. Mater. 2011, 13, B256-B260. [CrossRef]

16. López-Píriz, R.; Solá-Linares, E.; Rodriguez-Portugal, M.; Malpica, B.; Díaz-Güemes, I.; Enciso, S.; Esteban-Tejeda, L.; Cabal, B.; Granizo, J.J.; Moya, J.S.; et al. Evaluation in a dog model of three antimicrobial glassy coatings: Prevention of bone loss around implants and microbial assessments. PLoS ONE 2015, 10, e0140374. [CrossRef] [PubMed]

17. Cabal, B.; Alou, L.; Cafini, F.; Couceiro, R.; Sevillano, D.; Esteban-Tejeda, L.; Guitián, F.; Torrecillas, R.; Moya, J.S. A new biocompatible and antibacterial phosphate free glass-ceramic for medical applications. Sci. Rep. 2014, 4, 5440. [CrossRef] [PubMed]

18. Esteban-Tejeda, L.; Zheng, K.; Prado, C.; Cabal, B.; Torrecillas, R.; Boccaccini, A.R.; Moya, J.S. Bone tissue scaffolds based on antimicrobial $\mathrm{SiO}_{2}-\mathrm{Na}_{2} \mathrm{O}-\mathrm{Al}_{2} \mathrm{O}_{3}-\mathrm{CaO}-\mathrm{B}_{2} \mathrm{O}_{3}$ glass. J. Non-Cryst. Solids 2016, 432, $73-80$. [CrossRef]

19. López-Esteban, S.; Bartolomé, J.F.; Díaz, L.A.; Esteban-Tejeda, L.; Prado, C.; López-Piriz, R.; Torrecillas, R.; Moya, J.S. Mechanical performance of a biocompatible biocide soda-lime glass-ceramic. J. Mech. Behav. Biomed. Mater. 2014, 34, 302-312. [CrossRef] [PubMed]

20. ISO 22196:2011 Measurement of Antibacterial Activity on Plastics and Other Non-Porous Surfaces; International Organization for Standardization: Geneva, Switzerland, 2011.

21. Cheng, L.; Zhang, K.; Zhou, C.C.; Weir, M.D.; Zhou, X.D.; Xu, H.H.K. One-year water-ageing of calcium phosphate composite containing nano-silver and quaternary ammonium to inhibit biofilms. Int. J. Oral Sci. 2016, 8, 172-181. [CrossRef] [PubMed]

22. Zhang, K.; Li, F.; Imazato, S.; Cheng, L.; Liu, H.; Arola, D.D.; Bai, Y.; Xu, H.H.K. Dual antibacterial agents of nano-silver and 12-methacryloyloxydodecylpyridinium bromide in dental adhesive to inhibit caries. J. Biomed. Mater. Res. Part B Appl. Biomater. 2013, 101B, 929-938. [CrossRef] [PubMed]

23. Cherchali, F.Z.; Mouzali, M.; Tommasino, J.B.; Decoret, D.; Attik, N.; Aboulleil, H.; Seux, D.; Grosgogeat, B. Effectiveness of the DHMAI monomer in the development of an antibacterial dental composite. Dent. Mater. 2017, 33, 1381-1391. [CrossRef] [PubMed]

24. Beyth, N.; Yudovin-Farber, I.; Bahir, R.; Domb, A.J.; Weiss, E.I. Antibacterial activity of dental composites containing quaternary ammonium polyethylenimine nanoparticles against Streptococcus mutans. Biomaterials 2006, 27, 3995-4002. [CrossRef] [PubMed]

25. Zhang, J.F.; Wu, R.; Fan, Y.; Liao, S.; Wang, Y.; Wen, Z.T.; Xu, X. Antibacterial dental composites with chlorhexidine and mesoporous silica. J. Dent. Res. 2014, 93, 1283-1289. [CrossRef] [PubMed] 
26. Rathke, A.; Staude, R.; Muche, R.; Haller, B. Antibacterial activity of a triclosan-containing resin composite matrix against three common oral bacteria. J. Mater. Sci. Mater. Med. 2010, 21, 2971-2977. [CrossRef] [PubMed]

27. Ali, S.; Sangi, L.; Kumar, N. Exploring antibacterial activity and hydrolytic stability of resin dental composite restorative materials containing chitosan. Technol. Health Care 2017, 25, 11-18. [CrossRef] [PubMed]

28. Grischke, J.; Eberhard, J.; Stiesch, M. Antimicrobial dental implant functionalization strategies-A systematic review. Dent. Mater. J. 2016, 35, 545-558. [CrossRef] [PubMed]

29. Goudouri, O.M.; Kontonasaki, E.; Lohbauer, U.; Boccaccini, A.R. Antibacterial properties of metal and metalloid ions in chronic periodontitis and peri-implantitis therapy. Acta Biomater. 2014, 10, 3795-3810. [CrossRef] [PubMed]

30. Tauböck, T.T.; Zehnder, M.; Schweizer, T.; Stark, W.J.; Attin, T.; Mohn, D. Functionalizing a dentin bonding resin to become bioactive. Dent. Mater. 2014, 30, 868-875. [CrossRef] [PubMed]

31. Khvostenko, D.; Hilton, T.J.; Ferracane, J.L.; Mitchell, J.C.; Kruzic, J.J. Bioactive glass fillers reduce bacterial penetration into marginal gaps for composite restorations. Dent. Mater. 2016, 32, 73-81. [CrossRef] [PubMed]

(C) 2018 by the authors. Licensee MDPI, Basel, Switzerland. This article is an open access article distributed under the terms and conditions of the Creative Commons Attribution (CC BY) license (http:/ / creativecommons.org/licenses/by/4.0/). 